\title{
A Kieserita melhora a fertilidade e nutrição de plantas em laranjeiras
}

A Kieserita é um fertilizante de disponibilidade imediata. O magnésio utilizado em grande quantidade pelas plantas para o seu desenvolvimento reprodutivo. O enxofre desempenha papel fundamental na formação da parte vegetativa e na frutificação. O objetivo do estudo foi avaliar a aplicação de Kieserita nos atributos químicos do solo e no desenvolvimento vegetativo, nutricional e qualidade dos frutos da laranja. O delineamento experimental adotado foi em blocos ao acaso, sendo os tratamentos constituídos pelas doses de Kieserita (0,280, 560, 840 e 1120 g planta-1) parcelada em duas aplicações em cobertura, com três repetições. A Kieserita proporcionou melhorias nas qualidades físico-químicos dos frutos e nos atributos químicos do solo aos 6 (pH, Mg, CTC) e $12 \mathrm{meses}(\mathrm{P}$ e K). Na planta os teores foliares de $\mathrm{Mg}$ e $\mathrm{S}$ apresentaram incremento com as doses de Kieserita. Nas condições edafoclimáticas de cultivo da laranja a dose de máxima eficiência variou de 560 a 840 g planta-1.

Palavras-chave: Citrus Sinensis; Manejo da Adubação; Atributos de Qualidade.

\section{Kieserita improves fertility and nutrition of plants in orange}

Kieserite is a readily available fertilizer. Magnesium is widely used by plants for their reproductive development. Sulfur plays a fundamental role in the formation of the vegetative part and in the fruiting. The objective of this study was to evaluate the application of Kieserita on soil chemical attributes and on vegetative, nutritional development and quality of orange fruits. The experimental design was randomized blocks, and the treatments consisted of the doses of Kieserita ( 0 , 280, 560, 840 and $1120 \mathrm{~g}$ plant-1) split in two applications with three replications. Kieserita provided improvements in the physicochemical qualities of fruits and soil chemical attributes at $6(\mathrm{pH}, \mathrm{Mg}, \mathrm{CTC})$ and 12 months ( $\mathrm{P}$ and $\mathrm{K})$. In the plant the leaf contents of $\mathrm{Mg}$ and $\mathrm{S}$ increased with the doses of Kieserita. Under the edaphoclimatic conditions of orange cultivation the maximum efficiency dose ranged from 560 to $840 \mathrm{~g}$ plant-1.

Keywords: Citrus Sinensis; Fertilization Management; Quality Attributes.

Topic: Desenvolvimento, Sustentabilidade e Meio Ambiente

Reviewed anonymously in the process of blind peer.
Received: 02/12/2019

Approved: $16 / 01 / 2020$
Danielly Cristina da Silva Marques Universidade Federal Rural da Amazônia, Brasil http://lattes.cnpq.br/2322411633474060 marquesdanielly@hotmail.com

Ricardo Shigueru Okumura (iD)

Universidade Federal Rural da Amazônia, Brasil http://lattes.cnpq.br/2875667291793150

http://orcid.org/0000-0002-5079-3980

ricardo_okumura@hotmail.com

Eduardo Cezar Medeiros Saldanha (iD)

Universidade Federal Rural da Amazônia, Brasil

http://lattes.cnpq.br/3178287096907197

http://orcid.org/0000-0002-3593-6939

ecmsaldanha@yahoo.com.br

\author{
Daiane de Cinque Mariano (iD \\ Universidade Federal Rural da Amazônia, Brasi \\ http://lattes.cnpq.br/0458398387101131 \\ http://orcid.org/0000-0002-3875-150X \\ daianedecinque@gmail.com \\ Cândido Ferreira de Oliveira Neto (iD) \\ Universidade Federal Rural da Amazônia, Brasil \\ http://lattes.cnpq.br/0327663489224028 \\ http://orcid.org/0000-0002-6070-0549 \\ candidooliveiraneto@gmail.com \\ Ismael de Jesus Matos Viégas \\ Universidade Federal Rural da Amazônia, Brasil \\ http://lattes.cnpq.br/5645151005844327 \\ http://orcid.org/0000-0001-7212-1977 \\ matosviegas@hotmail.com
}

Deusdedith Cruz Filho

Universidade Federal Rural da Amazônia, Brasil

http://lattes.cnpq.br/3014469010050445

deusdedith.filho@ufra.edu.br
Referencing this:

MARQUES, D. C. S.; OKUMURA, R. S.; SALDANHA, E. C. M.; MARIANO, D. C.; OLIVEIRA NETO, C. F.; VIÉGAS, I. J. M.; CRUZ FILHO, D.. A Kieserita melhora a fertilidade e nutrição de plantas em laranjeiras. Revista Ibero Americana de Ciências Ambientais, v.11, n.1, p.321332, 2020. DOI: http://doi.org/10.6008/CBPC21796858.2020 .001 .0029 


\section{INTRODUÇÃO}

A citricultura brasileira é um dos setores mais competitivos e de maior potencial de crescimento do agronegócio, sendo o país considerado o terceiro maior produtor mundial de frutas frescas e o maior produtor mundial de citros, onde a produção no Brasil foi de 16.677.091 toneladas, o estado do Pará atua neste cenário como o sexto maior produtor (IBGE, 2019).

O polo citrícola no Estado do Pará apresenta solos de baixa fertilidade natural, ácidos e com baixa saturação por bases, associado a exportação de nutrientes pelas frutas (FIDALSKI et al., 2008), necessitando a aplicação das elevadas doses de fertilizantes para a produção de frutos, ocasionando danos ao meio ambiente e aumento dos custos de produção (OLIVEIRA et al., 2009).

A nutrição com magnésio e enxofre é frequentemente negligenciada, sendo que a deficiência do nutriente ocasionado por baixos valores no solo e/ou induzida por níveis elevados de elementos antagônicos, potássio e cálcio, inibem fortemente a absorção pelas plantas, no caso do Mg (VERBRUGGEN et al., 2013), promovendo desordem nutricional generalizada, influenciando no crescimento das plantas, produtividade e a qualidade dos frutos de laranja. O cultivo intensivo de solos com baixo teor de matéria orgânica e de argila, a utilização de fertilizantes concentrados e a exportação contínua de $\mathrm{Mg}$ e $\mathrm{S}$, sem reposição dos nutrientes promove diminuição na disponibilidade dos elementos para as plantas (SILVA et al., 2013).

Experimentos com fontes de fertilizantes na disponibilidade de magnésio e enxofre foram realizados para definir a eficiência da adubação química, nutrição de plantas, produtividade e qualidade de frutos (NEUHAUS et al., 2014; JEZEK et al., 2015). No entanto, ainda são escassos experimentos em campo que avaliem a aplicação de produtos de origem natural em citros, considerando a existência de grandes áreas citrícolas de baixo fornecimento de $\mathrm{Mg}$ e de $\mathrm{S}$, a Kieserita tem apresentando com alto potencial de utilização agrícola fornecedor dos nutrientes na forma de sulfato.

A Kieserita (sulfato de magnésio) é um mineral mono-hidrato de sulfato de magnésio $\left(\mathrm{MgSO}_{4} \cdot \mathrm{H}_{2} \mathrm{O}\right)$, peso molecular de 138,8 $\mathrm{g} \mathrm{mol}^{-1}$ (KALI, 2013), de ocorrência natural e obtido a partir de extração de minérios de potássio (HARDTER et al., 2004), contendo 25\% de magnésio e $20 \%$ de enxofre de disponibilidade imediata (RIASCOS, 2004). De acordo com Marin et al. (2008), a Kieserita aumenta o teor de magnésio no solo, chegando a valores capazes de suprir as necessidades nutricionais da planta e melhor equilíbrio químico no solo, facilitando a absorção pela planta (MARIN et al., 2008).

A utilização de um fertilizante contendo $\mathrm{Mg}$ e $\mathrm{S}$ de origem natural, granulado e solúvel, de disponibilidade imediata, pode contribuir para a melhoria dos atributos químicos e qualidade dos frutos. Diante disto, o trabalho avaliou a aplicação de Kieserita nos atributos químicos do solo e no desenvolvimento vegetativo, nutricional e qualidade de frutos da laranja cultivados nas condições edafoclimáticas de Capitão Poço/PA.

\section{MATERIAIS E MÉTODOS}

O experimento foi conduzido em área de produção comercial de citros, no município de Capitão 
Poço, no Estado do Pará ( $1^{\circ} 44^{\prime} 47^{\prime \prime} S ; 47^{\circ} 3^{\prime} 57^{\prime}$ ' O). A área experimental foi constituída por um pomar de laranjeiras da variedade 'Pera Rio' (Citrus sinensis [L.] Osbeck.), enxertadas em limão-cravo (Citrus limonia Osbeck), com altura média de 2,5 m, apresentando 4 anos de idade. 0 solo é do tipo Latossolo Amarelo distrófico, textura média (EMBRAPA, 2018). Segundo a classificação de Köppen, o clima do município é do tipo Ami, com precipitação anual em torno de $2.500 \mathrm{~mm}$, com uma curta estação seca entre setembro e novembro (precipitação mensal em torno de $60 \mathrm{~mm}$ ), temperatura média de $26^{\circ} \mathrm{C}$ e umidade relativa do ar entre $75 \%$ e $89 \%$ nos meses com menor e maior precipitação, respectivamente, sendo que no período experimental as condições climáticas estão apresentadas na Figura1.

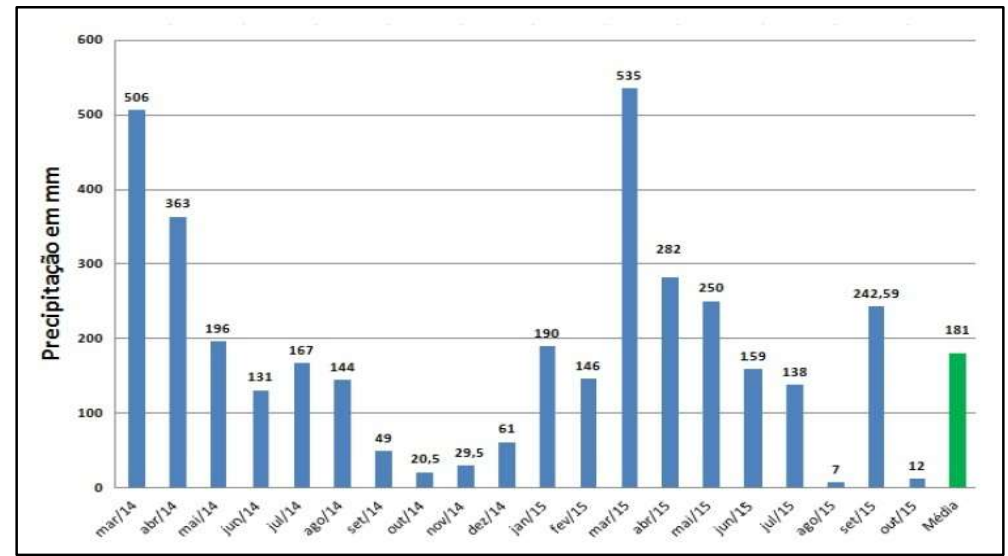

Figura 1: Precipitação observada durante o período de avaliação do experimento no município de Capitão Poço/PA.

O delineamento experimental utilizado foi blocos casualizados, com cinco tratamentos e três repetições, totalizando quinze parcelas experimentais. Cada tratamento foi constituído de 16 parcelas totalizando 240 plantas, espaçadas em $7 \times 4 \mathrm{~m}$, cuja área da parcela foi de $448 \mathrm{~m}^{2}$, totalizando $1344 \mathrm{~m}^{2}$. Os tratamentos consistiram de cinco doses de ESTA Kieserita: 0; 280; 560; 840 e 1120 g planta $^{-1}$, a escolha dos tratamentos foi realizado de acordo com a análise do solo da área de estudo. A adubação foi parcelada em duas aplicações, fornecidas às plantas, ocorrendo a primeira em abril e a segunda em junho de 2014 com intervalos de 60 dias entre as aplicações, baseadas nas indicações de Viégas et al. (1989).

Foram coletadas amostras de solos na área experimental em profundidades 0-20 e 20-40 cm, na linha da cultura (projeção da copa) e na entrelinha do pomar (entre copas), 30 dias antes da aplicação do fertilizante, e 6 meses e 12 meses após a aplicação. As amostras depois de coletadas foram submetidas à secagem ao ar, destorroamento e passadas em peneira de tela galvanizada com abertura de $2 \mathrm{~mm}$, em que as 25 amostras simples se formou uma única amostra composta, que foi encaminhada ao laboratório para determinação da granulometria e atributos químicos para caracterizar o estado de fertilidade do solo e de modo avaliar a necessidade de aplicação de magnésio caso o teor fosse menor que $0,5 \mathrm{cmol}_{\mathrm{c}} \mathrm{dm}^{-3} \mathrm{de}_{\mathrm{a}}$ magnésio no solo, seguindo a recomendação de adubação e calagem para o Estado do Pará (CRAVO et al., 2010).

Analisaram-se atributos químicos: matéria orgânica (M.O.); potencial hidrogeniônico (pH); fósforo (P) e potássio (K) disponíveis, cálcio (Ca), alumínio trocáveis (Al); acidez potencial $(\mathrm{H}+\mathrm{Al})$; soma das bases (SB); capacidade de troca de cátions (CTC); porcentagem de saturação por bases trocáveis (V\%) e saturação 
por $\mathrm{Al}(\mathrm{m} \%)$, e a granulometria do solo (areia, silte e argila). Os atributos químicos determinados foram: $\mathrm{pH}$ em $\mathrm{CaCl}_{2}$ 0,1 mol L-1; $\mathrm{MO}$ pelo método Walkley-Black modificado, $\mathrm{P}, \mathrm{Ca}$, $\mathrm{Mg}$ e $\mathrm{K}$ extraídos com resina trocadora de íons; $\mathrm{Al}$ trocável extraído com $\mathrm{KCl} 1 \mathrm{~mol} \mathrm{~L}^{-1} ; \mathrm{H}+\mathrm{Al}$ extraído com tampão SMP. Quanto à granulometria, foram determinados os teores de areia, silte e argila pelo método da pipeta de acordo com a Embrapa. As análises químicas e os cálculos seguiram os procedimentos contidos em Raij et al. (2001). Aos 6 e 12 meses após a aplicação das doses de Kieserita foram realizadas amostragens foliares, selecionando a terceira ou quarta folhas do ramo frutífero com frutos de $2 \mathrm{~cm}$ a $4 \mathrm{~cm}$ de diâmetro no terço médio da copa das plantas selecionadas, de acordo com a metodologia referida por Malavolta (2006), de modo a monitorar o comportamento do magnésio e enxofre na planta. Foram realizadas 03 coletas de amostras composta de 4 folhas por tratamento, de modo a atender os princípios de repetibilidade estatística. O material vegetal foi colocado em sacos de papel, etiquetado e levado à estufa de circulação forçada de ar a $65^{\circ} \mathrm{C}$ até massa constante para então serem moídas em moinho tipo Willey, e encaminhadas ao laboratório, para determinação dos teores totais de macro e micronutrientes. Os teores de nutrientes nas folhas foram determinados da seguinte forma: o nitrogênio total das amostras foi determinado pelo método micro Kjeldahl, de acordo com a metodologia citada por Malavolta (2006). No extrato, obtido por digestão nitroperclórica, foram medidos os níveis de $\mathrm{P}$ total por colorimetria; os teores de $\mathrm{Ca}, \mathrm{Mg}, \mathrm{Cu}, \mathrm{Fe}, \mathrm{Mn}$ e $\mathrm{Zn}$ foram medidos por espectrofotometria de absorção atômica; o conteúdo de K, por fotometria de chama, os de S por turbidimetria e o teor de B foi extraído por digestão seca (SILVA, 2009; EMBRAPA, 2009).

Os frutos foram colhidos manualmente, no estádio de maturação, no mês de agosto, caracterizado por ser a safra 'temporã', em 30 plantas, sendo 10 frutos por planta, totalizando 300 frutos, da porção mediana de cada planta descartando a bordadura e acondicionados em sacos plásticos higienizados. Após a colheita, os frutos foram encaminhados ao laboratório e avaliados a qualidade físico-química, sendo: a) diâmetro $(\mathrm{cm})$, b) volume de suco $(\mathrm{mL}), \mathrm{c}$ ) massa dos frutos $(\mathrm{g})$, d) sólidos solúveis (oBrix), e) pH, e f) produtividade de frutos $\left(\mathrm{t} \mathrm{ha}^{-1}\right)$.

Os dados experimentais obtidos foram inicialmente submetidos aos testes de Shapiro-Wilks e de Levene $(p<0,01)$ para verificação da normalidade e homocedasticidade residuais, respectivamente. Posteriormente, atendidas as pressuposições básicas, realizou-se a análise de regressão polinomial, observando-se a significância pelo teste $F(p<0,05)$ da análise de variância e do teste t de Student $(p<0,05)$, por meio do software estatístico SISVAR (FERREIRA, 2011).

\section{RESULTADOS E DISCUSSÃO}

Para o diâmetro do fruto em função de doses de Kieserita, verificou que na ausência da adubação o diâmetro médio do fruto foi de $68,2 \mathrm{~mm}$, ocorrendo um incremento com a adição do fertilizante, com a dose de máxima eficiência técnica de $590 \mathrm{~g} \mathrm{planta}^{-1}$ (Figura 2). Os valores de diâmetro dos frutos encontrados no presente estudo $(68,2$ a 70,0 mm) apresentaram dimensões satisfatórias e estão de acordo com o recomendado pelo Programa Brasileiro de Modernização da Horticultura (2011), que determina valores de 65 a $71 \mathrm{~mm}$, considerado adequado para laranjas de mesa do tipo Pêra. 


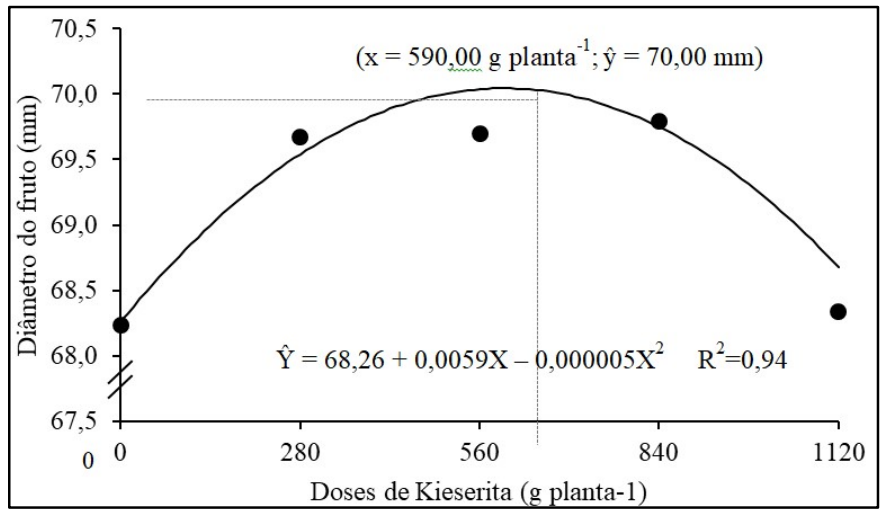

Figura 2: Diâmetro de frutos de laranjeiras Pêra-Rio em função da aplicação de doses crescentes de Kieserita em Capitão Poço/PA.

Por meio dos resultados obtidos da massa do fruto (Figura 3) verificou melhor ajuste à equação quadrática, com a dose máxima de eficiência técnica de 544,11 g planta ${ }^{-1}$ de Kieserita para o incremento de 189,79 g. A aplicação de Kieserita influenciaram positivamente na massa dos frutos, sendo de fundamental importância a característica para os citricultores, pois a comercialização é realizada pela relação massa/reais. Assim, a aplicação de doses de Kieserita proporcionou um maior desenvolvimento no diâmetro dos frutos, o que resultou em maior massa de fruto, consequentemente em ganhos na produção pelos citros. As médias de massa dos frutos (aproximadamente de 190g) estão enquadradas nos padrões para o mercado de laranjas in natura, cujos frutos devem apresentar o mínimo de $150 \mathrm{~g}$ (DOMINGUES et al., 2003).

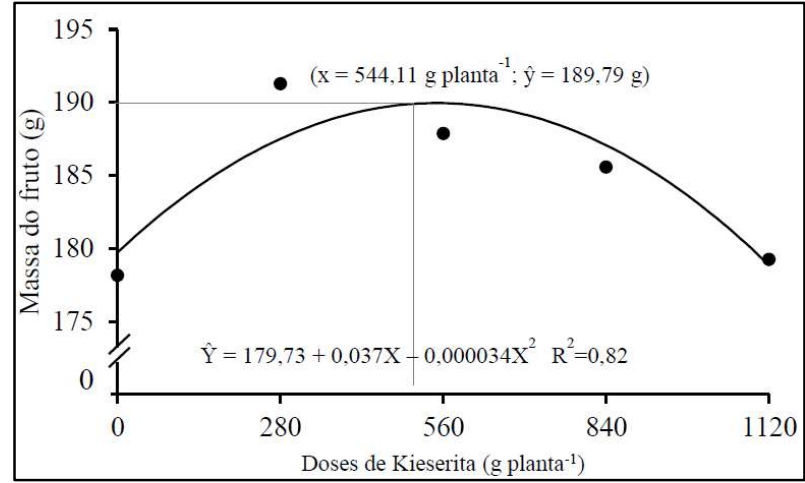

Figura 3: Massa de frutos de laranjeiras Pêra-Rio em função da aplicação de doses crescentes de Kieserita em Capitão Poço/PA.

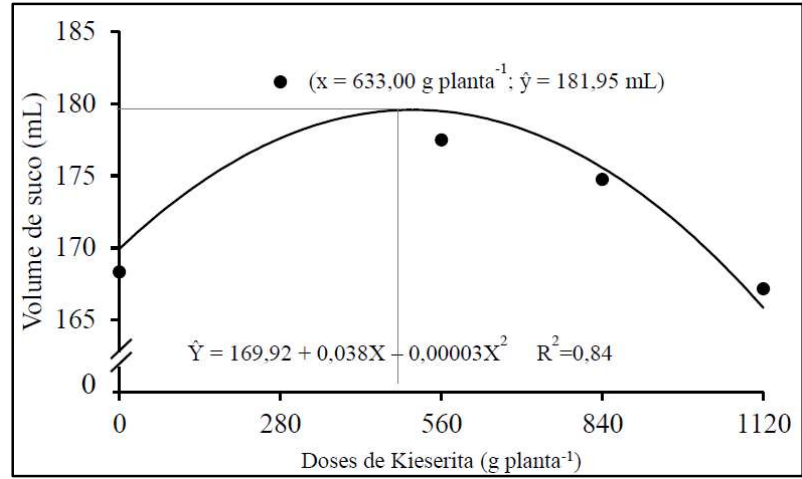

Figura 4: Volume do suco de frutos de laranjeiras PêraRio em função da aplicação de doses crescentes de Kieserita em Capitão Poço/PA.

O benefício da Kieserita ocorre devido a presença do Mg desempenhar funções na fotossíntese, agindo como percursor estrutural da molécula de clorofila e atividor da principal enzima da fotossíntese Rubisco Carboxilase (TAIZ et al., 2017), aumentando a taxa fotossintética líquida da planta. Enquanto, a disponibilidade de enxofre, por atuar na formação de proteinas e moléculas importantes, está envolvido em processos enzimáticos e reações de oxirredução, assim como constituinte dos aminoácidos cisteína e metionina, que constituem cerca de $90 \%$ do total de S na planta (MALAVOLTA, 2006). Para a variável volume de suco (Figura 4), verificou-se que abs doses de Kieserita influenciaram na variável, volume de suco, com o melhor ajuste da equação quadrática, em que a máxima eficiência técnica de 181,95 mL foi obtida na dose de $633 \mathrm{~g}$ planta $^{-1}$. O alto rendimento em suco é uma característica importante para as cultivares de laranjas, tanto para as que são utilizadas para o consumo 'in natura' como para aquelas para industrialização. 
Resultados semelhantes do efeito benéfico do magnésio em citros foi relatado por Dawood et al. (2001), em que observaram incremento no volume de suco.

Por meio da Figura 5, verificou-se que o @Brix foi significativamente influenciado pela aplicação de doses de Kieserita com melhor ajuste da equação quadrático, em que o valor de 12,16 @Brix foi obtida na dose de 600,00 g planta $^{-1}$. Os valores obtidos no presente estudo estão próximos aos descritos por Donadio (1995) que foram de 11,8 e 12 Brix, respectivamente, e superiores aos valores considerados mínimos pela CEAGESP (2012) que são de 10Brix.

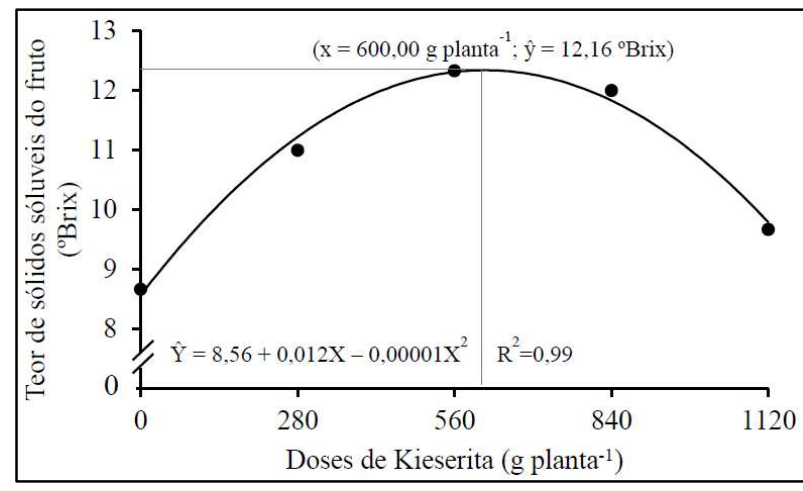

Figura 5: Teor de sólidos solúveis de frutos de laranjeiras Pêra-Rio em função da aplicação de doses crescentes de Kieserita em Capitão Poço/PA.

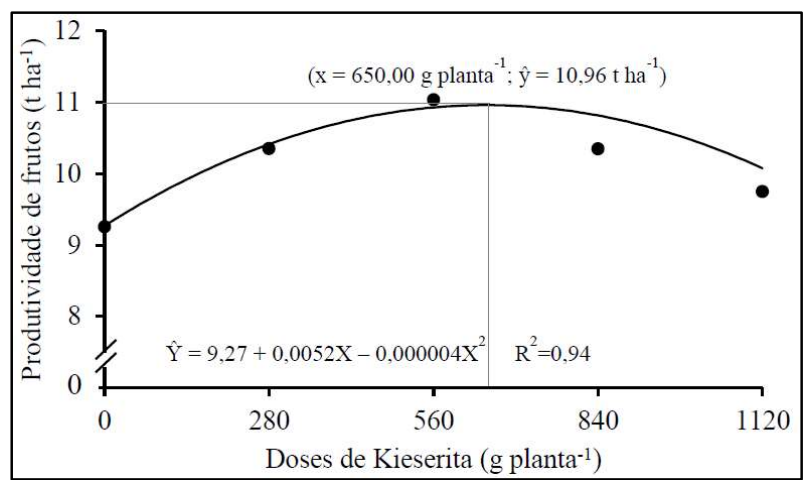

Figura 6: Produtividade da cultura da laranja em função das doses crescentes de Kieserita em Capitão Poço/PA.

De acordo com Kluge et al. (2002) os teores de sólidos solúveis são compostos solúveis em água e importantes para se determinar a qualidade da fruta, representam a quantidade de açúcares, ácidos, vitaminas, aminoácidos e pectina existentes no fruto. Cada 1 을 Brix equivale a $1 \mathrm{~g}$ de sólidos dissolvidos em $100 \mathrm{~g}$, assim, um fruto de laranja com teor de 10 @Brix apresenta $10 \mathrm{~g}$ de sólidos solúveis, dissolvidos em 100 g de suco, ou 10\% de concentração de sólidos solúveis (HORTIBRASIL, 2009).

As doses de Kieserita na produtividade de frutos (Figura 6) apresentaram melhor ajuste para equação quadrática, assim, o aumento nas doses do nutriente promoveu aumento na produtividade de frutos com posterior redução, verificando que a máxima eficiência técnica de $10,96 \mathrm{t} \mathrm{ha}^{-1}$ de frutos foi obtida na dose de 650,00 g planta $^{-1}$ de Kieserita. Uma das características da Kieserita é sua alta solubilidade em água, baixa reatividade com o solo, possui uma elevada disponibilidade inicial e maior suscetibilidade à lixiviação. Essas características intrínsecas da fonte proporcionaram reflexos quanto ao tamanho dos frutos avaliados pelo seu diâmetro revelando que a fonte mais solúvel proporcionou maior disponibilidade inicial e efeito no parâmetro avaliado.

Veloso et al. (2000) estudando citros no Nordeste paraense observaram que o Mg exerceu influência na produtividade da laranjeira, para pomares de baixa produtividade menores que $30 \mathrm{t} \mathrm{ha}^{-1}$, e que as maiores limitações nutricionais por deficiência nos pomares de laranjeira de baixa produtividade obedecem respectivamente à seguinte ordem decrescente para os macronutrientes: $\mathrm{Ca}>\mathrm{Mg}>\mathrm{K}>\mathrm{S}>\mathrm{N}>\mathrm{P}$. $\mathrm{O}$ teor de fósforo no solo submetido às doses de Kieserita, em dois períodos de avaliação (Figura 7), apresentou aos 6 meses uma redução dos valores de $\mathrm{P}$, com valor mínimo de $6,00 \mathrm{cmol}_{\mathrm{c}} \mathrm{dm}^{-3}$, e a avaliação aos 12 meses 
resultou em incrementos lineares nos teores de $\mathrm{P}$, com os valores de mínimo e máximo variando de 5,00 a $8,00 \mathrm{cmol}_{\mathrm{c}} \mathrm{dm}^{-3}$ nas doses de 0 a $1120 \mathrm{~g} \mathrm{planta}^{-1}$, respectivamente.

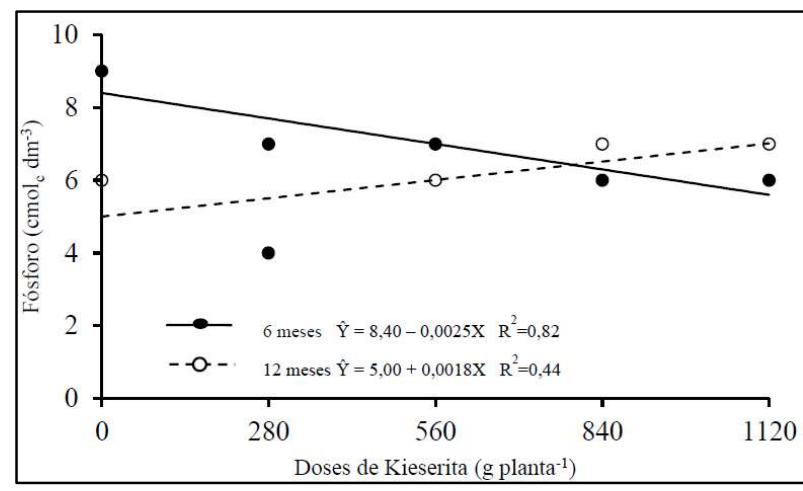

Figura 7: Concentração de Fósforo no solo, na profundidade de $0,2 \mathrm{~m}$, em função dos tratamentos, em pomares com laranjeira 'Pêra-Rio', referente à medida aos 6 meses e 12 meses após a aplicação de Kiesserita.

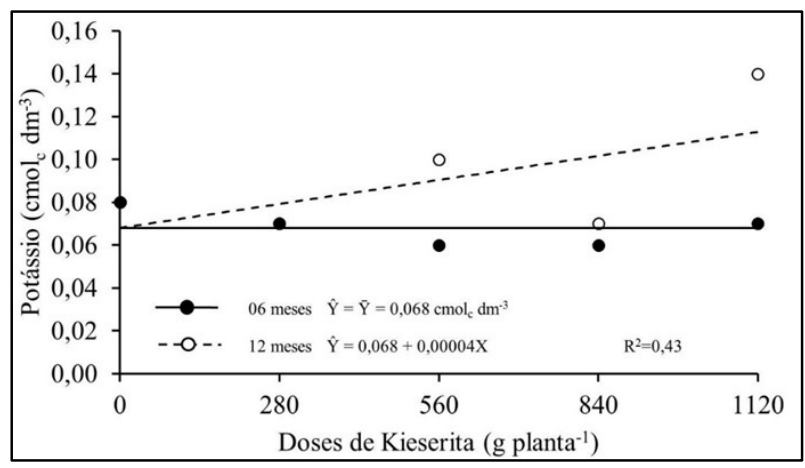

Figura 8: Concentração de potássio no solo na profundidade de 0,2 m, em função dos tratamentos, em pomares com laranjeira 'Pêra-Rio', referente à medida aos 6 meses e 12 meses após a aplicação de Kieserita.

O conhecimento das concentrações químicas dos nutrientes no solo, associado à análise do tecido foliar é de fundamental importância para qualquer tipo de cultura, pois é fator primordial para a caracterização da fertilidade do solo e do estado nutricional das plantas, que são fatores determinantes da produtividade das culturas, pois o equilíbrio nutricional da planta reflete no aumento de produtividade (OLIVEIRA et al., 2009).

Com relação aos teores de $\mathrm{K}$ no solo (Figura 8), no período de 6 meses não foram influenciadas pela aplicação de kieserita. Os teores disponíveis de K na solução do solo ficaram dentro da faixa considerada

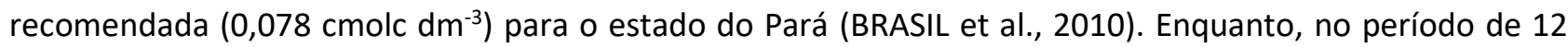
meses após a aplicação de Kieserita verificou que o modelo de regressão que melhor se ajustou aos dados foi a linear. De acordo com Wadt et al. (1999) o movimento do cátion $\mathrm{K}^{+}$no solo depende do tipo de solo e, na maioria dos casos, move-se com limitação, podendo, no entanto, ser movimentado para as camadas superficiais em solos arenosos e com baixa CTC e na presença de ânions fracamente adsorvidos, como sulfatos.

Para os teores de Ca no solo (Figura 9), verificou-se que as concentrações de Ca no solo não foram influenciadas pelas doses crescentes de kieserita, independente do período de avaliação ter ocorrido aos 6 ou 12 meses, apresentando valores médios de 1,20 e 0,70 $\mathrm{cmol}_{\mathrm{c}} \mathrm{dm}^{-3}$, respectivamente. Os teores disponíveis de Ca estão abaixo da faixa recomendada para o estado do Pará, que é de 2,0 a 5,0 $\mathrm{cmolc} \mathrm{dm}^{-3}$ (BRASIL et al., 2010). A aplicação de Kieserita no solo apresentaram aos 6 meses (Figura 10), melhor ajuste da equação quadrática, com a máxima eficiência técnica de $0,68 \mathrm{cmol}_{\mathrm{c}} \mathrm{dm}^{-3}$ obtida na dose de $916,67 \mathrm{~g}$ planta ${ }^{-1}$, teor considerada média $(0,5-1,5)$ para magnésio no solo, conforme o manual de recomendações e adubação e Calagem para o Estado do Pará (CRAVO et al., 2010). Raij et al. (1997) concluiu que valores de magnésio de 0,5 a $0,9 \mathrm{cmol}_{\mathrm{c}} \mathrm{dm}^{-3}$ é considerado médio em solo específico para citros.

Para a avaliação realizada aos 12 meses, verificou-se que os teores não foram diferentes estatisticamente, com teor médio de $0,20 \mathrm{cmol}_{\mathrm{c}} \mathrm{dm}^{-3}$. Possivelmente, o $\mathrm{Mg}$ liberado rapidamente sofreu 
perdas por lixiviação quando aplicado ao solo, sob condições de alta pluviosidade, como é o caso das condições edafoclimáticas do local de estudo. Outra possível explicação para a diminuição dos teores de Mg no solo, pode ser resultante da lixiviação, por causa dos baixos valores de pH do solo (DELBEM et al., 2011), ocorrendo a diminuição na disponibilidade de magnésio (CRAVO et al., 2010).

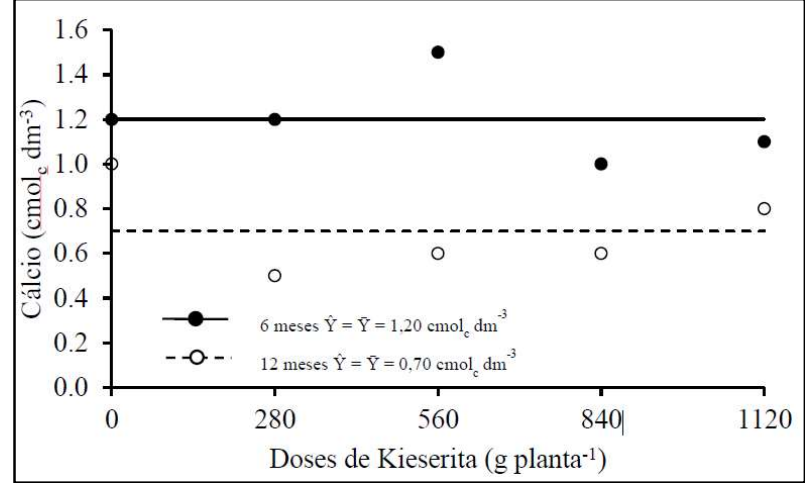

Figura 9: Concentração de Cálcio no solo, na profundidade de $0,2 \mathrm{~m}$, em função dos tratamentos, em pomares com laranjeira 'Pêra-Rio', referente à medida aos 6 meses e 12 meses após a aplicação de Kiesserita.

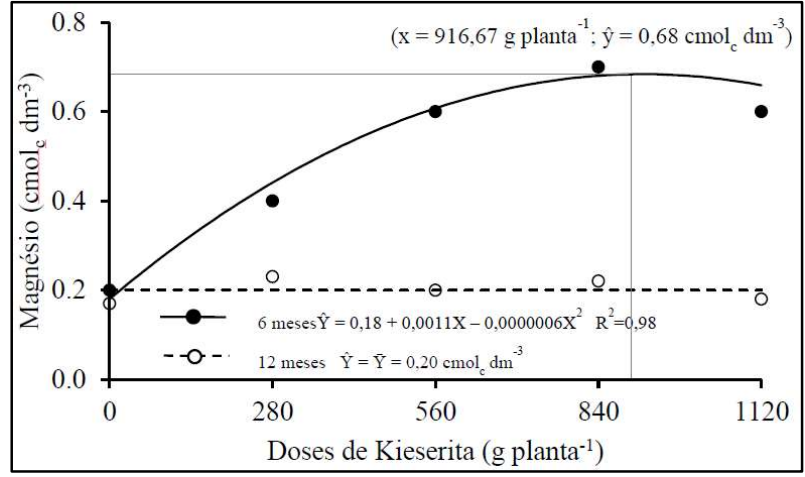

Figura 10: Concentração de magnésio no solo, na profundidade de $0,2 \mathrm{~m}$, em função dos tratamentos, em pomares com laranjeira 'Pêra-rio', referente à medida aos 6 meses e 12 meses após a aplicação de Kieserita.

Pelas informações da Figura 10, verificou-se que na avaliação aos 6 meses de aplicação do Kieserita, o melhor ajuste da equação foi o quadrático, com o valor máximo de $3,47 \mathrm{cmolc} \mathrm{dm}^{-3}$ obtida na dose de 450,00 g planta $^{-1}$. A CTC é influenciada pelos valores de Mg e K, o que reforça os resultados apresentados, assim, o incremento nos teores de $\mathrm{Mg}$ e K na solução do solo promoveram um maior preenchimento destes elementos na CTC do solo, em contrapartida, retirando os elementos acidificantes $\mathrm{como}^{+}$e $\mathrm{Al}^{+3}$. Enquanto, a avaliação da CTC no período de 12 meses, apresentou ajuste da equação linear negativa. Possivelmente, a competição dos nutrientes aos sítios de trocas, promovidos pelas doses de Kieserita e a alta solubilidade no solo, ocasionaram efeito reverso da CTC do solo.

A saturação por bases foram influenciados pelas doses de Kieserita aplicados no solo para os dois períodos de avaliação, 6 meses e 12 meses, apresentando o melhor ajuste da regressão linear (Figura 12). Para a avaliação aos 6 meses os valores de saturação por bases variaram de 48 a $58 \%$, sendo o valor considerados adequados (60\%) para a cultura do citrus (VIOLANTE NETO et al., 1988; MALAVOLTA et al., 1989). De Raij et al. (1997), o ideal seria manter os solos dos pomares nas classes de teores médios, evitando, assim, a deficiencia ou excesso pois ambos podem limitar a produtividade e a qualidade dos frutos. $\mathrm{Na}$ avaliação aos 12 meses, os valores de V\% foram inferiores comparativamente aos 6 meses, variando de 25 a $38 \%$, proporcionados pelos baixos valores observados para as variáveis $\mathrm{K}, \mathrm{Mg}$ e CTC do solo.

Para os teores de K nas folhas (Figura 13), verificou-se efeito de diminuição linear nos teores na avaliação aos 6 meses, com o máximo e mínimo valor de 11,2 e 9,6 g kg ${ }^{-1}$ obtido com nas doses de 280 e 1120 g planta ${ }^{-1}$, respectivamente. Apesar de apresentar teores considerados adequados no solo, não promoveram incrementos no tecido foliar, uma possível justificativa foi o efeito competitivo entre os nutrientes, $\mathrm{Ca}, \mathrm{Mg}$ e K, pelo mesmo sítio ativo de absorção (QUAGGIO et al., 2011). 


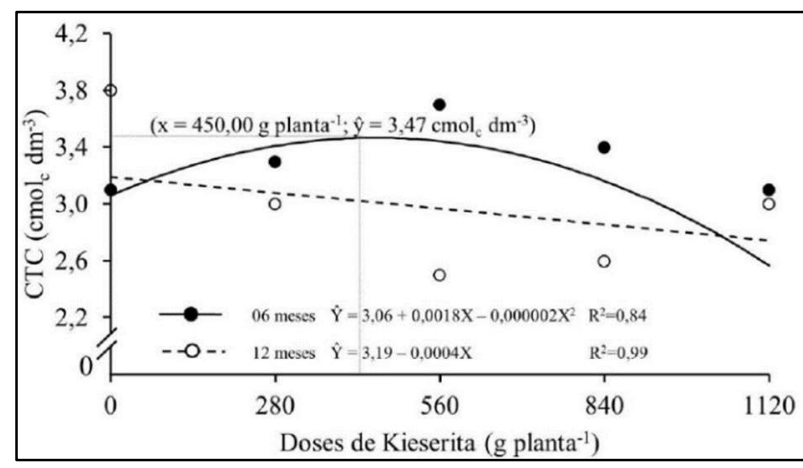

Figura 11: Valores de CTC de amostras de solo (0-20m) tratadas com doses crescentes de Kieserita aos 6 meses e 12 meses dias após a aplicação.

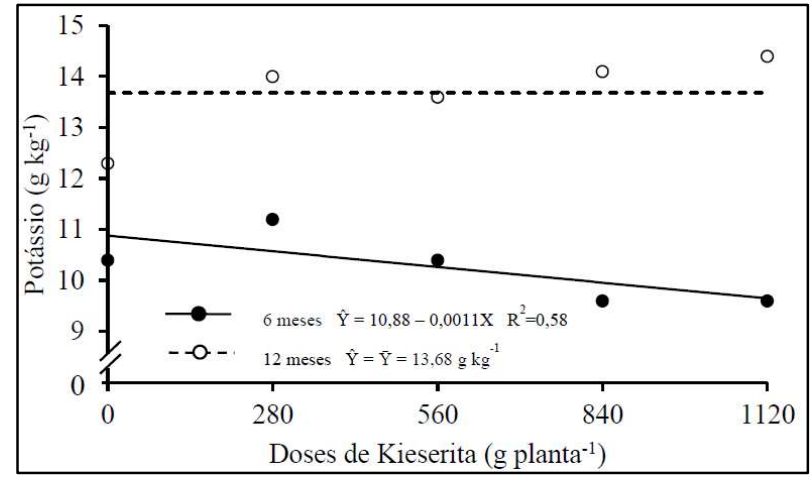

Figura 13: Teores de potássio no tecido vegetal de laranjeiras amostradas aos 6 meses e 12 meses após a aplicação de doses crescentes de Kieserita.

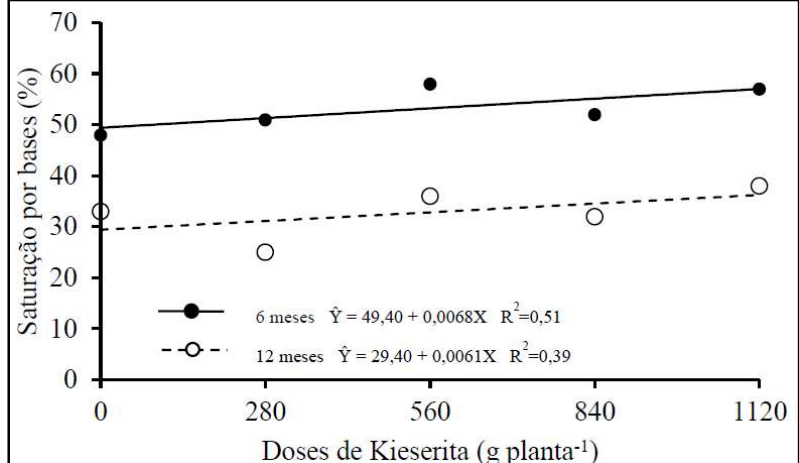

Figura 12: Valores de Saturação por bases de amostras de solo $(0-20 \mathrm{~m})$ tratadas com doses crescentes de Kieserita aos meses e 12 meses após a aplicação.

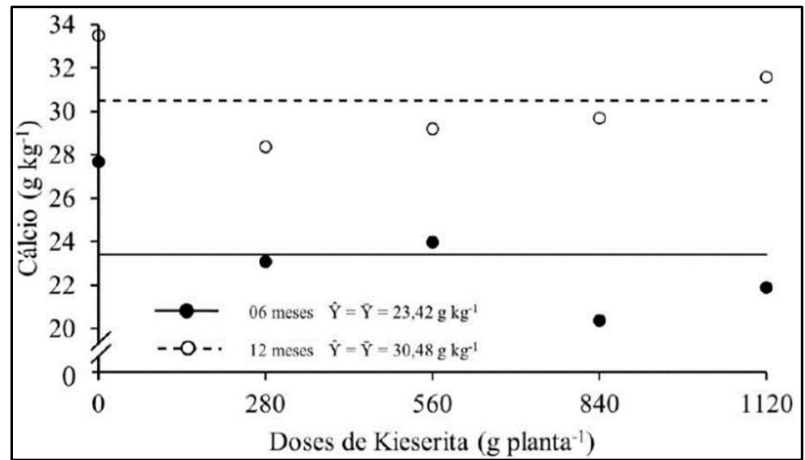

Figura 14: Teores de cálcio no tecido vegetal de laranjeiras amostradas aos 6 meses e 12 meses dias após a aplicação de doses crescentes de Kieserita.

Enquanto, na avaliação aos 12 meses não foi verificado diferença estatística nos teores de $\mathrm{K}$ da folha pela aplicação de Kieserita, apresentando valor médio de $13,86 \mathrm{~g} \mathrm{~kg}^{-1}$, considerado adequado $\left(0,10 \mathrm{mg} \mathrm{kg}^{-1}\right)$ (CRAVO et al., 2010). Os padrões nutricionais apresentam discrepâncias relacionadas às diferenças das condições edafoclimáticas dos locais de estudo, por exemplo o nível crítico de K nas folhas por Quaggio et al. (2011) foi de $13 \mathrm{~g} \mathrm{~kg}^{-1}$, enquanto Dias et al. (2013), estimaram em 7,0 $\mathrm{g} \mathrm{kg}^{-1}$, o que demonstra a importância em definir os padrões nutricionais para cada região produtora de citros.

O teor foliar de cálcio (Figura 14), aos 6 meses, não apresentou diferença estatística, com valor médio de $23,42 \mathrm{~g} \mathrm{~kg}^{-1}$, valores inferiores aos considerados adequados $\left(35-40 \mathrm{~g} \mathrm{~kg}^{-1}\right)$ para o desenvolvimento dos citros (QUAGGIO et al., 2005). A avaliação aos 12 meses, mostra que os teores foliares não foi influenciado pelas doses crescentes de kieserita, valores médios de $27,32 \mathrm{~g} \mathrm{~kg}^{-1}$, valores considerados baixos para a cultura dos citros por Malavolta et al. (1989), que é de 30 a $49 \mathrm{~g} \mathrm{~kg}^{-1}$. A absorção do Ca pelas plantas pode estar sendo inibida pelos níveis elevados de $\mathrm{Mg}$, elemento antagônico que competem pelo mesmo sítio de absorção, refletindo nos teores foliares do presente trabalho.

Na análise foliar aos 6 meses após a aplicação de Kieserita (Figura 15), verificou que o teor de magnésio nas folhas de laranjeira Pêra, apresentaram o melhor ajuste da equação quadrática, com a máxima eficiência técnica de 3,86 $\mathrm{g} \mathrm{kg}^{-1}$ obtida na dose de $866,67 \mathrm{~g}$ planta-1 de $\mathrm{Mg}$, valor nas faixas consideradas adequadas por Cravo et al. (2010). O teor de magnésio, na segunda avaliação, aos 12 meses proporcionou ajuste da regressão linear crescente, com os valores de 2,7 e 3,5 $\mathrm{g} \mathrm{kg}^{-1}$, dentro da faixa considerada ideal nas 
folhas 2,5 - 4,0 $\mathrm{g} \mathrm{kg}^{-1}$ (MATTOS JÚNIOR et al., 2001; QUAGGIO et al., 2005; VELOSO et al., 2010). Resultado semelhante foram descritos por Veloso et al. (2000), estudando citros no Nordeste paraense, observaram que os teores médios de $\mathrm{Mg}$ em folhas de laranjeira de baixa produção foram de $4,6 \mathrm{~g} \mathrm{~kg}^{-1} \mathrm{de} \mathrm{Mg}$.

Pelas informações do presente estudo, verificou que o magnésio, fornecido ao solo pela adubação, após absorvido pelas raízes apresentou alta mobilidade no floema, sendo translocado dentro da planta para locais de alta demanda de nutrientes, refletindo em aumentos nos teores nas folhas, participando dos processos fisiológicos e bioquímicos da planta (SENBAYRAM et al., 2015).

Observa-se uma diminição da massa até um determinado ponto, podendo ser explicado por meio da analise foliar, em que ocorreu uma diminuição nos teores de $\mathrm{Ca}$ e $\mathrm{K}$, por ser tratarem de elementos antagônicos na absorção pelas plantas, uma adubação equilibrada entre esses três nutrientes é de fundamental importancia para plantas e para os frutos.

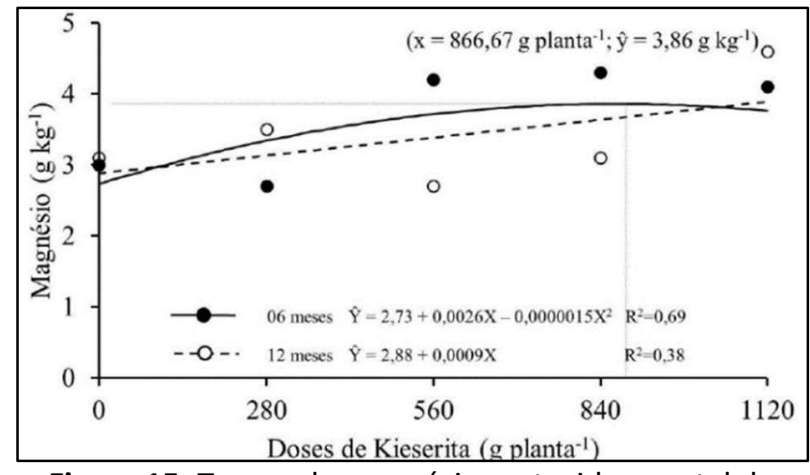

Figura 15: Teores de magnésio no tecido vegetal de laranjeiras amostradas aos 6 e 12 meses após a aplicação de doses crescentes de Kieserita.

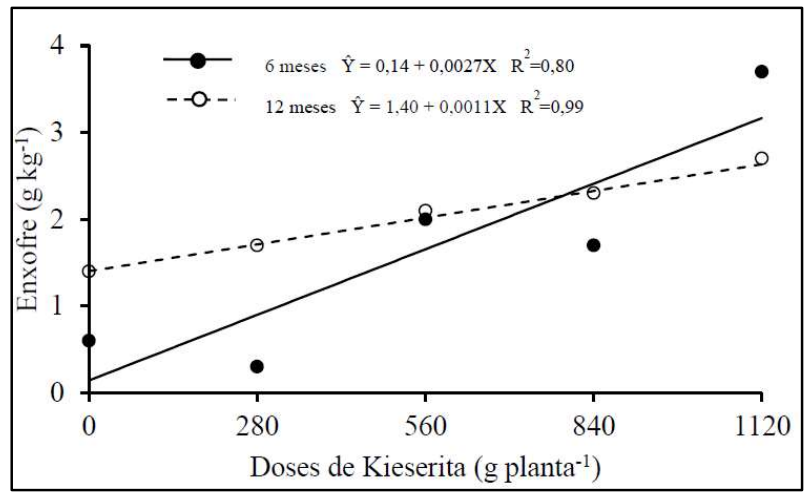

Figura 16: Teores de enxofre no tecido vegetal de laranjeiras amostradas aos 6 e 12 meses após a aplicação de doses crescentes de Kieserita.

Para o teor de $\mathrm{S}$ foliar, verificou-se que, independente do período avaliado, proporcionaram ajuste da regressão linear crescente, em que aos 6 meses os valores variaram de 0,3 a 3,7 g kg-1, enquanto aos 12 meses dias foram de 1,4 a $2,7 \mathrm{~kg}^{-1}$ (Figura 16). Os valores obtidos para o $\mathrm{S}$ estão na faixa considerados adequados por Veloso et al. (2010), de 2 a $3 \mathrm{~g} \mathrm{~kg}^{1}$ de S. Os teores de $\mathrm{Mg}$ e S aumentaram de forma linear com o aumento das doses de Kieserita, justificada pela presença de $\mathrm{Mg}$ e S na composição do fertilizante (RIASCOS, 2004), mostrando a importância da aplicação da Kieserita, principalmente nos solos deficientes em S, comumente identificada no Brasil.

\section{CONCLUSÕES}

A aplicação de kieserita proporciona melhorias nas qualidades físico-químicos dos frutos exceto para o $\mathrm{pH}$, além de influenciar positivamente promovendo aumentos nos atributos químicos do solo $(\mathrm{pH}, \mathrm{Mg}, \mathrm{CTC})$ no período de 6 meses após a aplicação e nos teores $\mathrm{P}$ e $\mathrm{K}$ do solo, nos períodos de 12 meses após a aplicação. Os teores foliares de Mg e $\mathrm{S}$ aumentam com as doses de kieserita. Enquanto, os teores de $\mathrm{K}$ e Ca na folha variam conforme as doses aplicadas. Nas condições edafoclimáticas do experimento a dose recomendada de kieserita é de 560 a $840 \mathrm{~g}_{\text {planta }}{ }^{-1}$. 


\section{REFERÊNCIAS}

CEAGESP. Centro de Qualidade de Hortigranjeiro. Ficha da Laranja 'pera'. São Paulo: CEAGESP, 2012.

CRAVO, M. S.; VIÉGAS, ISMAEL, J. M.; BRASIL, E. C.. Recomendação de adubação e calagem para o estado do Pará. Belém: Embrapa Amazônia Oriental, 2010.

DAWOOD, S. A.; EL-HAMADY, M. M.; EL-SIADA, S. A. G.; HAMISSA, A. M.. Response of Washington Navel orange trees grown on slightly alkaline clay soils to magnesium rates, methods and number of applications. Egyptian Journal of Agricultural Research, v.79, p.1059-1073, 2001.

DIAS, J. R. M.; TUCCI, C. A. F.; WADT, P. G. S.; SILVA, A. M.; SANTOS, J. Z. L.. Níveis críticos e faixas de suficiência nutricional em laranjeira-pêra na Amazônia Central obtidas pelo método DRIS. Acta Amazônica, v.43, n.3, p.239-246, 2013.

DOMINGUES, E. T.; TULMANN NETO, A.; TEÓFILO SOBRINHO, J.; MATTOS JUNIOR, D.; POMPEU JUNIOR, J.; FIGUEIREDO, J. O.. Seleção de variedades de laranja quanto à qualidade do fruto e período de maturação. Laranja, Cordeirópolis, v.24, n.2, p.471-470, 2003.

DONADIO, L. C.; FIGUEIREDO, J. O.; PIO, R. M.. Variedades cítricas brasileiras. Jaboticabal: FUNEP, 1995.

EMBRAPA. Empresa Brasileira de Pesquisa Agropecuária. Manual de análises químicas de solos, plantas e fertilizantes. 2 ed. Brasília: Embrapa Informação Tecnológica, 2009.

EMBRAPA. Empresa Brasileira de Pesquisa Agropecuária. Sistema brasileiro de classificação de solos. 5 ed. Rio de Janeiro: Centro Nacional de Pesquisa de Solos, 2018.

FERREIRA, D. F.. Sisvar: a computer statistical analysis system. Ciência \& Agrotecnologia, Lavras, v.35, n.6, p.10391042, 2011.

FIDALSKI, J.; AULER, P. A. M.. Alterações químicas temporais nas faixas de adubação e entrelinhas do pomar, nutrição e produção de laranja após calagem superficial. Revista Brasileira de Ciência do Solo, Viçosa, v.32, n.2, p.689-696, 2008.

HARDTER, R.; REX, M.; ORLOVIUS, K.. Effects of different $\mathrm{Mg}$ fertilizer sources on the magnesium availability in soils. Nutrient Cycling in Agroecosystems, v.70, p.249-259, 2004.

HORTIBRASIL. Laranja. 2009.

IBGE. Instituto Brasileiro de Geografia e Estatística. Banco de dados. Rio de Janeiro: IBGE, 2019.

JEZEK, M.; GEILFUS, C. M.; BAYER, A.; MÜHLING, K. H.. Photosynthetic capacity, nutrient status, and growth of maize (Zea mays I.) Upon $\mathrm{mg} \mathrm{so}_{4}$ leaf-application. Front. Plant. Sci., v.5, p.1-10, 2015.

KLUGE, R. A.; NACHTIGAL, J. C.; FACHINELLO, J. C.; BILHAVA, A. B.. Fisiologia e manejo pós-colheita de frutas de clima temperado. 2 ed. Campinas: Rural, 2002.
MALAVOLTA, E.. Manual de nutrição mineral de plantas. São Paulo: Ceres, 2006.

MALAVOLTA, E.; VIOLANTE NETTO, A.. Nutrição mineral, calagem, gessagem e adubação dos citros. Piracicaba: POTAFÓS, 1989.

MARIN, N.; PLAZA, G.; ROJAS, J.. Evaluación técnica y económica de alternativas de fertilización y enmiendas en tabaco Virginia (Nicotiana tabacum) en la región García Rovira, Santander (Colombia). Agron. Colomb., v.26, n.3, p.505-516, 2008

NEUHAUS, C.; GEILFUS, C.-M.; MÜHLING K.-H.. Increasing root and leaf growth and yield in Mg-deficient faba beans (Vicia faba L.) by $\mathrm{MgSO}^{4}$ foliar fertilization. J. Plant Nutr. Soil Sci., v.177, p.741-747, 2014.

OLIVEIRA, P. C. G.; FARIAS, P. R. S.; LIMA, H. V.; FERNANDES, A. R. F. A.; JAVIER, D. P.. Variabilidade espacial de propriedades químicas do solo e da produtividade de citros na Amazônia Oriental. Rev. Bras. Eng. Agríc. Ambient., v.13, n.6, p.708-715, 2009.

PBMH. Programa Brasileiro para Modernização da Horticultura. Normas de classificação de citros de mesa. São Paulo: CEAGESP, 2011.

QUAGGIO, J. A.; MATTOS JUNIOR., D.; CANTARELLA, H.. Manejo da fertilidade do solo na citricultura. In: MATTOS JUNIOR, D.; NEGRI, J. D.; PIO, R. M.; POMPEU JUNIOR, J.. Citros. Campinas: Instituto Agronômico e Fundag, 2005. p.483-507.

QUAGGIO, J. A.; MATTOS JUNIOR, D.; BOARETTO, R. M.. Sources and rates of potassium for sweet orange production. Scientia Agrícola, v.68, p.369-375, 2011.

RIASCOS, R. G.. Propiedades generales de los fertilizantes solidos. Manual técnico. 4 ed. Bogota: Monomeros Colombo-Venezolanos, 2004.

SENBAYRAM, M.; GRANSEE, A.; WAHLE, V.; THIEL, H.. Role of magnesium fertilisers in agriculture: Plant-soil continuum. Crop and Pasture Science, v.66, p.1219-1229, 2015.

SILVA, F. C.. Manual de análises químicas de solos, plantas e fertilizantes. 2 ed. Brasília: Embrapa Informação Tecnológica, 2009.

SILVA, M. L. S.; PICCOLO, M. C.; TREVIZAM, A. R.. Gypsum as a source of sulfur for strawberry crops. Semina: Ciências Agrárias, v.34, n.4, p.1683-1694, 2013.

TAIZ, L.; ZEIGER, E.; MOLLER, I.; MURPHI, A.. Fisiologia e desenvolvimento vegetal. 6 ed. Porto Alegre: Artmed, 2017.

VELOSO, C. A. C.; BOTELHO, S. M.; RODRIGUES, J. E. L. F.. Amostragem e Diagnose Foliar. In: CRAVO, M. S.; VIÉGAS, I. J. M.; BRASIL, E. C.. Recomendação de adubação e calagem para o estado do Pará. Belém: Embrapa Amazônia Oriental, 2000. p.49-55. 
VELOSO, C. A. C.; BOTELHO, S. M.; RODRIGUES, J. E. L. F..

Correção da acidez do solo. In: CRAVO, M. S.; VIÉGAS, I. J. M.; BRASIL, E. C.. Recomendação de adubação e calagem para o estado do Pará. Belém: Embrapa Amazônia Oriental, 2010. p.93-103.

VeRBRUGGEN, N.; HeRMANS, C.. Physiological and molecular responses to magnesium nutritional imbalance in plants. Plant and Soil, v.368, n.1, p.87-99, 2013.
VIÉGAS, I. J. M.; CUNHA, R. L. M.; CARVALHO, R. A. Avaliação de fontes de magnésio em porta-enxertos de seringueira. Boletim de pesquisa, n.7. Belém: EmbrapaUEPAE, 1989.

WADT, P. G. S.; WADT, L. H. O.. Movimentação de cátions em amostras de um Latossolo Vermelho- Amarelo incubadas com duas fontes de cálcio. Scientia Agrícola, Piracicaba, v.56, n.4, p.1.157-1.164, 1999.

A CBPC - Companhia Brasileira de Produção Científica (CNPJ: 11.221.422/0001-03) detém os direitos materiais desta publicação. Os direitos referem-se à publicação do trabalho em qualquer parte do mundo, incluindo os direitos às renovaç̃ões, expansões e disseminações da contribuiç̃o, bem como outros direitos subsidiários. Todos os trabalhos publicados eletronicamente poderão posteriormente ser publicados em coletâneas impressas sob coordenação da Sustenere Publishing, da Companhia Brasileira de Produção Científica e seus parceiros autorizados. Os (as) autores (as) preservam os direitos autorais, mas não têm permissão para a publicação da contribuição em outro meio, impresso ou digital, em português ou em tradução. 